\title{
Contabilidade e custos ambientais: um levantamento da produção científica no período de 1996 a 2007
}

\author{
Cleci Grzebieluckas ${ }^{\text {a*}}$, Lucila Maria de Souza Campos ${ }^{\mathrm{b}}$, \\ Paulo Mauricio Selig ${ }^{\mathrm{c}}$ \\ ${ }^{a *}$ cleci@unemat.br, UFSC, Brasil \\ blucila@deps.ufsc.br, UFSC, Brasil \\ 'selig@egc.ufsc.br, UFSC, Brasil
}

\begin{abstract}
Resumo
Esta pesquisa tem como objetivo analisar a produção científica sobre contabilidade e custos ambientais no período de 1996 a 2007. Para a classificação das temáticas foram utilizadas as palavras-chave: contabilidade ambiental; custos ambientais; environmental accounting; e environmental costs. Os parâmetros analisados foram: o tipo de estudo, a estratégia de pesquisa utilizada e a filiação acadêmica dos autores. Os resultados evidenciaram que houve um crescimento nas duas temáticas, passando de três estudos no ano de 1996 para dez no ano de 2007, totalizando 80 estudos no período. No geral, a temática custos ambientais ganhou maior atenção por parte dos pesquisadores representando 61\%, contra 39\% dos estudos que abordaram contabilidade ambiental. Constatou-se que, dos 148 autores identificados, 13 deles foram responsáveis por 48,75\% do total das publicações. A pesquisa procurou contribuir com a demonstração do estado da arte das temáticas em contabilidade e custos ambientais, no contexto nacional e internacional.
\end{abstract}

Palavras-chave

Contabilidade ambiental. Custos ambientais. Produção científica.

\section{Introdução}

A contabilidade, como ciência, teve crescimento significativo nos últimos anos observando-se uma evolução contínua em razão do aumento no número de programas de pós-graduação stricto sensu em contabilidade e, consequentemente, a crescente produção científica. A contabilidade ambiental é um ramo da contabilidade (YAKHOU; DORWEILER, 2004) e atualmente tem gerado interesse além dos limites acadêmicos e profissionais contábeis. Administradores, a mídia, políticos e o público em geral têm observado o ambiente e, por essas razões, problemas sociais podem ser tratados, pelo menos em parte, através da identificação, medição e avaliação da interação entre empresa e ambiente (MATHEWS, 1997).

A contabilidade impõe desafios de ordem informativa de medição, reconhecimento e valoração de cunho ambiental que comunguem com os interesses dos diversos segmentos supracitados. Para confirmar isso é necessário contar com informação precisa acerca dos custos ambientais que permitam elaborar indicadores financeiros ambientais confiáveis. Sánchez (2003) acredita que as diferentes metodologias da contabilidade ambiental contribuem para a construção de indicadores e valoração dos custos ambientais das empresas.

Embora a contabilidade ambiental tenha surgido há mais de 30 anos (MATHEWS, 1997, 2000), no Brasil somente na década de 90 iniciaram-se as primeiras publicações (CALIXTRO, 2005). 0 mapeamento dos trabalhos acadêmicos publicados na área de custos e contabilidade ambiental possibilita melhor compreensão de como a academia e as empresas tratam essas variáveis. Portanto, esta pesquisa tem como objetivo quantificar e conhecer a produção científica acadêmica em contabilidade e custos ambientais, no período de 1996 a 2007. Optou-se 
por estudar este período tendo em vista que Calixtro (2005) e Mathews $(1997,2000)$ já haviam realizado, em períodos anteriores, estudos semelhantes abordando estes temas.

Estudos desse tipo, sobre a produção científica, são comuns em várias áreas, tais como em recursos humanos (TONELLl et al., 2003), em marketing (VIEIRA, 2003), em gerência de operações (ARKADER, 2003) e em responsabilidade social (MORETT1; FIGUEIREDO, 2007). Na área da contabilidade, alguns estudos podem ser destacados, como os de Riccio, Carastan e Sakata (1999); Cardoso, Pereira e Guerreiro (2004); Cardoso et al. (2005); Martins e Silva (2005); Mendonça Neto, Riccio e Sakata (2006); Beuren, Schlindwein e Pasqual (2007), dentre outros. Todavia, não foram encontrados, pelos autores, estudos abordando a temática contabilidade e/ou custos ambientais, salvo o trabalho de Calixtro (2005), que fez uma análise das pesquisas sobre contabilidade ambiental no Brasil. No contexto internacional na área de contabilidade destacam-se os estudos de Mathews (1997), Ferreira e Merchant (1992), Ji (2000), Degos e Mattessich (2006), entre outros.

0 presente artigo está estruturado em quatro tópicos, além deste introdutório. 0 tópico a seguir apresenta o arcabouço teórico sobre contabilidade e custos ambientais. No terceiro tópico do artigo são mostrados os procedimentos metodológicos utilizados neste estudo. 0 quarto tópico apresenta e discute os principais resultados alcançados. Ao final do artigo, são relatadas suas considerações finais.

\section{Framework teórico sobre contabilidade e custos ambientais}

\subsection{Contabilidade ambiental}

Uma das grandes contribuições no campo da contabilidade social e ambiental no âmbito internacional foi dada por Mathews (1997), que fez uma revisão na literatura dos 25 anos de contabilidade social e ambiental. 0 autor fornece uma estrutura para permitir que leitores e pesquisadores organizem-se no tempo e evidenciem as tendências, oferecendo detalhes bibliográficos do início e interesse pelo estudo nesta área. 0 autor classifica seu estudo em três períodos que vão de 1971 a 1980, de 1981 a 1990 e de 1991 a 1995. Os subtítulos pesquisados por Matheus (1997) foram: estudos empíricos, demonstrações normativas, discussões filosóficas, a literatura não contábil, programas de educação, livros textos, estruturas regulamentadas e outras revisões da literatura.

Mathews (1997) comenta que nos anos 70 era subdesenvolvida a literatura relacionada à contabilidade social e ambiental. Todavia, essa situação começa a mudar na primeira parte da década de 80 devido ao aumento e qualidade dentro da área da contabilidade social, mas que somente na segunda metade da década houve uma transferência de interesses para a contabilidade ambiental. Mathews (1997) reporta que desde 1980 tem havido mudanças de foco com significativo acréscimo de especializações na literatura da contabilidade social e ambiental.

No último período de 1991 a 1995 assistiu-se a um avanço das questões ambientais dentro da contabilidade, incluindo interesses tanto dos gestores quanto dos contabilistas. Esse período foi caracterizado por quase uma completa dominação da contabilidade ambiental sobre a contabilidade social (MATHEWS, 1997).

Em um segundo estudo, Mathews (2000), usando a mesma metodologia adotada em 1997, analisou a literatura da contabilidade social e ambiental no período de 1995 a 2000. Em toda parte a ascendência da contabilidade ambiental sobre a contabilidade social vem se mantendo, contudo, esta última está sendo representada pela seção de auditoria social.

Calixtro (2005), inspirada em Mathews (1997, 2000), analisou as publicações brasileiras que abordaram a questão ambiental na literatura contábil no período de 1991 a 2004. A autora ordenou os estudos por tópicos como: a) contabilidade e meio ambiente; b) as primeiras propostas; c) mensuração dos ativos gastos e receitas ambientais; e d) pesquisa empírica em contabilidade ambiental.

Com base na verificação das obras analisadas sobre contabilidade ambiental, Calixtro (2005) concluiu que a pesquisa sobre o tema no Brasil é dificultada, devido a quatro fatores principais: $i$ ) as empresas que exercem atividades potencialmente poluidoras divulgam poucas informações sobre eventos ambientais; ii) a legislação brasileira é pouco rigorosa; iii) a maior parte das empresas é de responsabilidade limitada, dificultando o acesso aos seus relatórios contábeis; $\mathrm{e}$ iv) a gestão ambiental das empresas de grande porte já é uma realidade, mas a contabilidade ambiental não participa desses eventos.

Calixtro (2005) acredita que a contabilidade ambiental no Brasil primeiro virá por meio da conscientização de todos os profissionais da área para, em seguida, focar na divulgação no meio empresarial.

\subsection{Custos ambientais}

0 termo custo ambiental é de difícil conceituação - a literatura não apresenta uma definição clara e objetiva do que se considera como custo ambiental. A primeira dificuldade que se encontra ao trabalhar 
com os custos ambientais é o próprio fato de serem estes, em sua maioria, intangiveis.

[...] Custos intangíveis são aqueles custos com alto grau de dificuldade para serem quantificados, embora se perceba claramente a sua existência. (CALLADO, 2008, p. 4).

Motta (1996) destaca que os custos ambientais geralmente não são captados nas relações de mercado devido à indefinição de direitos privados de propriedade. Desse modo, o custo da degradação não incide sobre os que degradam, mas recai sobre a sociedade como um todo e sobre as gerações futuras. 0 autor salienta que o uso do meio ambiente gera externalidades que são custos ambientais não reconhecidos no sistema de preços e, portanto, externos às funções de custo e de demanda.

Shields, Beloff e Heller (2008) apontam que os custos ambientais são um subconjunto dos custos operacionais das empresas. Por exemplo, quando substâncias são lançadas no ar, água ou solo, resultando poluição, estas deveriam ser consideradas um custo social, ou seja; uma externalidade. Os autores exemplificam algumas dessas externalidades ambientais, tais como exigências de investimentos adicionais em equipamentos de prevenção ou formação, e multas ou taxas decorrentes do descumprimento das normas ambientais. Quando essas externalidades ambientais se tornam internalizadas surgem novos custos, sendo que estes devem ser obtidos através do sistema de contabilização de custos, de modo suficientemente correto para facilitar tomadas de decisões sólidas, uma vez que na maioria das vezes estão ocultos nas despesas gerais e subestimados (SHIELDS; BELOFF; HELLER, 2008).

Essa afirmativa é corroborada por Callado (2008), que aponta a existência de dificuldade para quantificar quaisquer custos ambientais, devido os mesmos demandarem uma contabilização mais detalhada. 0 autor comenta que na maioria dos casos esses custos existem, mas estão embutidos nos custos gerenciais da empresa. Campos (1996) identificou essa dificuldade quando estudou uma empresa do setor têxtil e verificou que a mesma alocava todos os custos aos produtos, não sendo possível com isso determinar as atividades desnecessárias e onerosas do processo produtivo. E no caso da relação entre o processo produtivo e o meio ambiente, não é possível saber quais são as atividades responsáveis pela poluição.

Ribeiro (2006) considera custos ambientais todos aqueles relacionados direta ou indiretamente com a proteção ambiental, tais como: a) a depreciação e exaustão dos ativos de natureza ambiental pertencentes à companhia; b) aquisição de insumos para controle, redução ou eliminação de poluentes; c) tratamento de resíduos dos produtos; d) disposição dos resíduos poluentes; e) recuperação ou reparo de áreas contaminadas; e f) mão de obra utilizada nas atividades de controle, prevenção ou recuperação do meio ambiente.

\subsection{Estudos sobre contabilidade e custos}

Riccio, Carastan e Sakata (1999) analisaram a distribuição e as características dos textos acadêmicos, incluindo dissertações e teses produzidas em quatro programas brasileiros de pós-graduação em contabilidade no período 1962-1999 nas instituições: Pontifícia Universidade Católica de São Paulo - PUC-SP, Universidade de São Paulo - USP, Fundação Getulio Vargas - FGV e Universidade Estadual do Rio de Janeiro - UERJ. A pesquisa focou a tendência no número de dissertações e teses, o método de pesquisa empregado e os tópicos abrigados pela área da contabilidade. Os autores identificaram 386 estudos distribuídos em 20 temáticas da contabilidade. Os tópicos contabilidade gerencial e financeira representaram respectivamente $21 \%$ e $18 \%$, enquanto contabilidade social e ambiental significou apenas 2\% do total dos estudos; esta constatação reforça a pesquisa de Calixtro (2005), onde destaca que a questão ambiental passou a ganhar interesse por parte dos pesquisadores somente a partir de 2000 .

Cardoso et al. (2005) analisaram a distribuição, as características metodológicas, a evolução e a temática das publicações científicas em contabilidade no período de 1990 a 2003 nas revistas nacionais "A" pela classificação da Coordenação e Aperfeiçoamento de Pessoal de Nivel Superior (CAPES). Nesse período foram publicados 2.037 estudos, dos quais 60 identificados como de contabilidade distribuídos em 11 áreas. As áreas identificadas foram: contabilidade de custos; contabilidade gerencial; contabilidade de mercados de capital; contabilidade pública; contabilidade tributária; orçamento; capital intelectual; contabilidade financeira; sistemas de informação; aspectos contemporâneos e planejamento financeiro. Observa-se que não foi encontrado nenhum estudo na área de contabilidade ou custos ambientais.

Martins e Silva (2005), por sua vez, analisaram a plataforma teórica utilizada pelos autores dos textos aprovados e divulgados nos $3^{\circ}$ e $4^{\circ}$ Congressos USP de Controladoria e Contabilidade, realizados nos anos de 2003 e 2004. Foram encontrados, em média, 17 referências por texto. Na concepção dos autores a bibliografia dos artigos revela uma postura extremamente conservadora e convencional visto que os pesquisadores raramente consultam periódicos, ignoram publicações de anais de congressos e ocasionalmente referenciam citações vindas de endereços eletrônicos. 
Beuren, Schlindwein e Pasqual (2007) estudaram o perfil da pesquisa em controladoria publicada em anais do Encontro da Associação Nacional de Pós-graduação e Pesquisa em Administração - EnANPAD e no Congresso USP de Controladoria e Contabilidade, no período de 2001 a 2006. Esses autores investigaram os temas abordados, os métodos de pesquisa adotados, as abordagens da controladoria estudados, a filiação dos pesquisadores e a bibliografia consultada e referenciada nos trabalhos. Os dados da pesquisa revelaram que houve um aumento gradativo, nesse período, do assunto controladoria nos eventos pesquisados. Contudo, os autores reportam que por se tratar de um tema importante dentro da contabilidade, esperava-se que as palavras controladoria, controller, contabilidade gerencial e controle gerencial estivessem mais presentes nos trabalhos de ambos os eventos.

No contexto internacional, Ferreira e Merchant (1992) realizaram um survey no campo da contabilidade e controle gerencial no período de 1984 a 1992. 0 estudo foi baseado em uma revisão de 11 periódicos de pesquisa contábil, duas séries de monografias, a coleção de papers apresentados em três colóquios de pesquisa em contabilidade de responsabilidade de Harvard Business School e as publicações em livros. Identificaram-se 82 estudos no período; desses, 34 (41\%) foram publicados nas coleções da Harvard Business School, 20 (24\%) no Accounting, Organizations and Society e os demais (35\%) foram distribuídos nas nove fontes de pesquisas analisadas. 0 estudo foi seguido por uma avaliação das escolhas dos pesquisadores por assunto, métodos e estilo de apresentação e interpretação dos dados. Os assuntos mais evidenciados no campo da pesquisa em contabilidade e controle gerencial foram custos, riscos e potencial de retorno.

Em 1979, a China reabriu as portas para o mundo externo e implementou uma série de reformas econômicas. Desde então, o crescimento econômico do país e a proporção do total do comércio mundial aumentaram significativamente. 0 sistema de contabilidade também foi alterado, a fim de satisfazer as necessidades da reforma econômica e do comércio internacional (Jl, 2000). Ji (2000) fez uma revisão dos estudos publicados em inglês no período de 1966 a 1998 e investigou as diferentes interpretações da contabilidade chinesa pelos estudiosos, tanto da China quanto de outros países. 0 autor também avaliou a importância desses estudos para o desenvolvimento da contabilidade internacional, e as conclusões foram que o desenvolvimento da contabilidade na China seria mais fechado para práticas internacionais e que as mudanças iriam ser fundamentais e dramáticas.

Nessa pesquisa, Ji (2000) identificou 91 estudos distribuídos em 14 temáticas e os separou em três períodos: 1966-1977, 1978-1992 e 1992-1998. No primeiro período o autor encontrou apenas dois estudos; no segundo, 38; e no terceiro o autor localizou 51 estudos sobre contabilidade. No segundo período, 1978-1992 prevaleceu a temática contabilidade financeira e relatórios com $21 \%$, seguida por contabilidade gerencial com 15\% do total de estudos do período. Já no terceiro período, 1992-1998, as temáticas padronizações contábeis e contabilidade financeira e relatórios representaram respectivamente $25 \%$ e $13 \%$ do total do período. Isso mostra que houve mudança de foco. Destaca-se que desses 91 estudos identificados como de contabilidade nenhum deles abordou a questão ambiental.

Degos e Mattessich (2006) realizaram um survey das publicações contábeis na literatura francesa no período 1950-2000. Os autores identificaram que nesse período diferentes aspectos da pesquisa em contabilidade foram examinados, tais como nas áreas acadêmica, social, matriz, eventos e história. Degos e Mattessich (2006) acreditam que talvez a subárea mais importante da contabilidade, na França, foi o plano de contas junto com seus revisores, particularmente com países europeus em processos legislativos de padronização e harmonização. $\mathrm{Na}$ percepção dos autores, na segunda metade do século XX, a influência francesa na teoria contábil decresce parcialmente devido ao surgimento da literatura da contabilidade inglesa e o surgimento excessivo de foco na padronização e, por conseguinte, a pesquisa acadêmica ficou negligenciada.

Já na área de custos, Cardoso, Pereira e Guerreiro (2004) traçaram o perfil da pesquisa em custos nos anais do EnANPAD no período 1998 a 2003. Os autores pesquisaram os temas abordados, o método de pesquisa adotado, os segmentos da área de custos estudados, a filiação acadêmica dos pesquisadores e o tipo de bibliografia consultada. Foram encontrados 32 trabalhos relacionados a custos, distribuídos em 12 tópicos; desses, 50\% tratavam do custo baseado em atividades ( $\mathrm{ABC}$ ) em suas aplicações, 12\% relacionados aos sistemas de custeios usados e 3,1\% abordavam o tema custo da qualidade ambiental caracterizando, portanto, um número reduzido de estudos sobre a questão ambiental.

Callado e Almeida (2005) analisaram o perfil dos artigos sobre custos no agronegócio publicados nos anais do Congresso Brasileiro de Custos no período 1994 a 2003. Os autores identificaram 58 artigos e avaliaram as seguintes variáveis: área temática dos trabalhos apresentados; publicação por instituição; região; pesquisador; métodos utilizados nos estudos; trabalhos por segmento econômico e classificação bibliográfica. As áreas temáticas identificadas foram: modelos de mensuração e gestão de custos no setor 
primário com 53,45\%; gestão estratégica de custos 8,62\%; custos e tomada de decisões 6,90\%; outras $17,24 \%$ e respectivamente custos para competitividade global; estudo de casos aplicados na área de custos; gestão de custos e sistemas de informação; sistemas de custeio com 3,45\%.

Quanto aos métodos dos estudos, a pesquisa bibliográfica representou 55\%, a pesquisa de campo 33\% e os estudos de caso 7\%. Os trabalhos por segmentos econômicos foram: explorações zootécnicas (avicultura e suinocultura); extração e exploração; vegetal e animal; agricultura; transformação de produtos agrícolas ou pecuários; pecuária e outras. No que tange à classificação bibliográfica, a predominância foi por livros nacionais, com $48,54 \%$ - e internacionais $8,90 \%$.

Schultz et al. (2006) avaliaram as pesquisas na área de custos no setor de serviços publicadas no EnANPAD e nos periódicos de administração e turismo classificados no Qualis A e B no período 2000 a 2004. Nos anais do EnANPAD os autores encontraram 2.737 artigos, e destes 9 tratavam de custos no setor de serviços. Quanto aos periódicos, num total de 12 foram identificados 1.380 artigos, e três deles abordavam custos no setor de serviços.

Verifica-se, portanto, que a questão ambiental ainda está muito aquém nos estudos tanto em contabilidade quanto em custos ambientais, exigindo maior atenção por parte tanto da academia quanto das empresas, visto ser uma variável que pode fornecer à empresa vantagem competitiva sustentável.

A seção a seguir apresenta os procedimentos metodológicos que conduziram a presente pesquisa.

\section{Procedimentos metodológicos}

Esta pesquisa é de natureza quantitativa descritiva e tem como objetivo mapear trabalhos acadêmicos publicados nas áreas de contabilidade e custos ambientais e, fundamentalmente, descrever o tipo de estudo (ensaio teórico, criação de um modelo ou estudo descritivo) e a estratégia (estudo de caso ou não identificado). Vale esclarecer que Godoi e Balsini (2004) classificam o tipo de pesquisa como quantitativo, qualitativo, quali-quantitativo e ensaio teórico; estratégia de pesquisa como estudo de caso, multicasos, documental, etnográfica, pesquisa-ação e participante. Para a classificação das pesquisas orientadas dentro da tipologia estudo de caso, Godoi e Balsini (2004) classificam como descritiva, exploratória e explanatória.

Para identificar os artigos relacionados à contabilidade e custos ambientais foram utilizadas palavras-chave tais como contabilidade ambiental, custos ambientais, environmental accounting e environmental costs. Os artigos cujo título apresentava a palavra custos ambientais ou environmental costs foram classificados como "estudos relacionados a custos ambientais" e os que apresentavam contabilidade ou environmental accounting foram classificados como "estudos relacionados à contabilidade ambiental".

Em seguida, estruturou-se uma pesquisa documental que analisou a produção científica nacional e internacional abordando as temáticas contabilidade e custos ambientais.

A amostra foi probabilística (aleatória) composta por 80 estudos distribuídos em 32 fontes de publicações entre anais, periódicos e programas de pós-graduação (Tabela 1). As fontes pesquisadas foram os periódicos: RAE - Revista de Administração de Empresas; RAC - Revista de Administração Contemporânea; RAUSP - Revista de Administração USP; RBE - Revista Brasileira de Economia; PPE - Pesquisa e Planejamento Econômico; RAP - Revista de Administração Pública; READ - Revista Eletrônica de Administração; RBC - Revista Brasileira de Contabilidade; RCF - Revista Contabilidade \& Finanças (USP), Revista do BNDES; Revista Pensar Contábil; Revista Universo Contábil, SciELO - Scientific Eletronic Library Online.

Outras fontes de divulgação foram os anais dos congressos e encontros como EnANPAD - Encontro Nacional de Pós-graduação e Pesquisa em Administração; ENEGEP - Encontro Nacional de Engenharia de Produção; ENGEMA - Encontro Nacional sobre Gestão Empresarial e Meio Ambiente; CBC - Congresso Brasileiro de Custos. Além dessas fontes foram pesquisadas as bibliotecas digitais da UFSC - Universidade Federal de Santa Catarina; da USP - Universidade de São Paulo; da UFRJ - Universidade Federal do Rio de Janeiro; da UFRGS - Universidade Federal do Rio Grande do Sul; da Unicamp - Universidade de Campinas; UNB - Universidade de Brasília; Banco de Teses CAPES; SciELO - Scientific Eletronic Library Online; Google Acadêmico e Base de Dados do Proquest.

A opção pelos periódicos e anais pesquisados se deu em função de serem áreas afins ao tema estudado e abordarem assuntos ligados à administração, contabilidade, economia e engenharias. Já as bibliotecas digitais e as demais fontes foram escolhidas aleatoriamente.

0 procedimento de análise de diversas fontes foi inspirado em Capon, Farley e Hoenig (1990), os quais por meio de meta análise encontraram 320 estudos na área de finanças. Os estudos encontrados por Capon, Farley e Hoenig (1990) apareceram em 65 periódicos, 19 livros, 17 dissertações, cinco working papers e dois anais da academia de gestão. 
Tabela 1. Fontes de comunicação e quantidade de estudos publicados nas áreas de contabilidade e custos ambientais no período de 1996/2007.

\begin{tabular}{|c|c|c|c|c|c|c|c|c|c|c|c|c|c|}
\hline & & & & & & & Anos & & & & & & \\
\hline Fontes & 1996 & 1997 & 1998 & 1999 & 2000 & 2001 & 2002 & 2003 & 2004 & 2005 & 2006 & 2007 & Total \\
\hline Dissertação - UFSC & 1 & & & & & & & & 1 & & & & 2 \\
\hline Dissertação - Unicamp & & 1 & & & & & & & & & & & 1 \\
\hline RAE & & 1 & & & & & & & & & & & 1 \\
\hline ENEGEP & 1 & 1 & & & & & & & 2 & 1 & & 1 & 5 \\
\hline Cong. Bras. de Custos & & & 1 & 3 & 2 & 3 & 6 & 2 & 4 & 6 & 1 & 3 & 31 \\
\hline Tese - Univ. UTAH - EUA & & & 1 & & & & & & & & & & 1 \\
\hline Cong. Intern. de Custos & & & & 1 & & & & & & & & & 1 \\
\hline Revista do BNDES & & & & 1 & & & & & & & & & 1 \\
\hline Tese - Univ. of N. York & & & & 1 & & & & & & & & & 1 \\
\hline Rev. Pensar Contábil & & & & & 2 & & & & & & & & 2 \\
\hline RBC & & & & & 1 & & 1 & & & 1 & & & 3 \\
\hline Anuário - F.C.E. & & & & & & 1 & & & & & & & 1 \\
\hline Aud. \& Ac Journal & & & & & & 1 & & & & & & & 1 \\
\hline EnANPAD & 1 & & & & & 1 & & 1 & 1 & & & & 4 \\
\hline Dissertação - USP & & & & & & 1 & & 1 & & & & & 2 \\
\hline Dissertação - UFRJ & & & & & & 1 & & & & & & & 1 \\
\hline Rev. Cont. e Finanças & & & & & & 1 & 1 & & 1 & & & & 3 \\
\hline Conv. de Contab - RS & & & & & & & & 1 & & & & & 1 \\
\hline Diss. N. Scotia - Canadá & & & & & & & & 1 & & & & & 1 \\
\hline Scientia et Technica & & & & & & & & 1 & & & & & 1 \\
\hline Act. Contable Faces & & & & & & & & & 1 & & & & 1 \\
\hline B. S. and the Environm. & & & & & & & & & 1 & & & & 1 \\
\hline Univ. of Maryland - EUA & & & & & & & & & & 1 & & & 1 \\
\hline Rev. Ciênc. Empresariais & & & & & & & & & & 1 & & & 1 \\
\hline Rev. Univ. Contábil & & & & & & & & & & 2 & & 1 & 3 \\
\hline J. of Business Ethics & & & & & & & & & & & 1 & & 1 \\
\hline J. of Cleaner Prod. & & & & & & & & & & & 1 & & 1 \\
\hline S. Cont. em Maringá & & & & & & & & & & & 1 & & 1 \\
\hline Rev. Chil. de Ingeniería & & & & & & & & & & & & 2 & 2 \\
\hline Custose@groneg. on line & & & & & & & & & & & & 1 & 1 \\
\hline Perspectiva. Econômica & & & & & & & & & & & & 1 & 1 \\
\hline Rev. Inst. Int. de Costos & & & & & & & & & & & & 1 & 1 \\
\hline Total & 3 & 3 & 2 & 6 & 5 & 9 & 8 & 7 & 11 & 12 & 4 & 10 & 80 \\
\hline
\end{tabular}

Fonte: dados da pesquisa.

Em uma segunda etapa foram analisados os resumos para identificação do tipo de estudo e a estratégia de pesquisa utilizada. Limitou-se a esses dois modelos tendo em vista que nem sempre é possivel identificar outros métodos de coleta de dados somente com a leitura dos resumos. Na ocorrência de publicação do mesmo estudo em anais e periódicos, quando identificados, foram computados somente os publicados em periódicos.

A filiação dos autores foi considerada pelo vínculo mencionado no momento da publicação. Na ausência desta informação foi utilizada a plataforma Lattes.

A partir das informações retiradas das fontes de publicação foram geradas as tabelas e figuras cujos resultados e informações são discutidos e interpretados no próximo tópico.

\section{Resultados da pesquisa}

Inicialmente são apresentadas na Tabela 1 as fontes de publicação, número de estudos por ano e o total de publicações encontrado na pesquisa.

A partir dos dados da Tabela 1 é possível observar que as temáticas contabilidade e custos ambientais passaram a ganhar maior atenção por parte dos pesquisadores no final do século XX e continuaram crescendo no século XXl, embora com algumas oscilações (Figura 1), vindo a sofrer queda brusca em 2006 e retomando em 2007. Essa queda foi influenciada pelos anais do Congresso Brasileiro de Custos, que naquele ano (2006) teve somente uma publicação na área, uma vez que representou quase $40 \%$ do total das publicações dos demais veículos de comunicação do período pesquisado 1996-2007. 


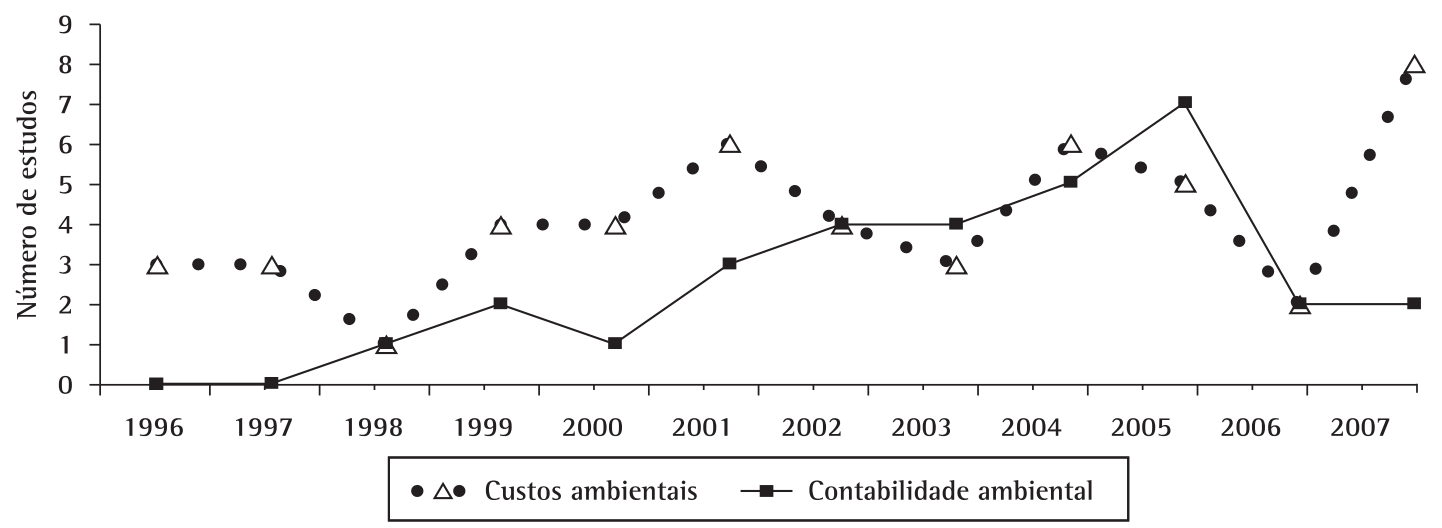

Figura 1. Estudos realizados por área temática. Fonte: dados da pesquisa.

Esse resultado corrobora Calixtro (2005), que destaca que somente em 2000 iniciou-se uma evolução na produção de estudos sobre a questão ambiental. Confirma também o estudo de Riccio, Carastan e Sakata (1999), que em 20 tópicos da contabilidade a temática contabilidade social e ambiental representou apenas $2 \%$ dos estudos contábeis. Outro dado interessante foi que os 80 estudos realizados foram distribuídos em 32 veículos de comunicação, uma média de 2,43 artigos por fonte de publicação.

Observando-se os dados relacionados ao EnANPAD (o maior evento da comunidade científica e acadêmica de administração no país), percebe-se um número reduzido de trabalhos abordando os temas de contabilidade e custos ambientais. Isso pode ser evidenciado no trabalho de Cardoso, Pereira e Guerreiro (2004). Esses autores fizeram um estudo no âmbito da contabilidade e controle gerencial publicados no EnANPAD, no período de 1998 a 2003, e perceberam que de um total de 32 artigos distribuídos em 12 temáticas foi encontrado somente um estudo no ano de 2001 (ROBLES JUNIOR; BONELLI, 2001), o que caracteriza que o tema ainda é incipiente.

Tal constatação também foi verificada no estudo de Callado e Almeida (2005), que analisaram o perfil dos artigos sobre custos no agronegócio e identificaram as áreas temáticas como: modelos de mensuração e gestão de custos no setor primário; gestão estratégica de custos; custos e tomada de decisões; custos para competitividade global; gestão de custos e sistemas de informação e sistemas de custeio. Observa-se que o termo "custos ambientais" não aparece em nenhuma das temáticas sobre custos levantados no ramo do agronegócio.

A Figura 1 apresenta a evolução dos estudos por temática realizados no período de 1996 a 2007.

Observa-se que as duas temáticas evoluíram, todavia, não de forma constante, visto que em 2000,
Tabela 2. Distribuição das temáticas dos estudos nacionais e internacionais. Fonte: dados da pesquisa.

\begin{tabular}{cccc}
\hline & \multicolumn{2}{c}{ Temática de estudos } & \multirow{2}{*}{ Total } \\
\cline { 2 - 3 } & Internacional & Nacional & \\
\hline Custo ambiental & 29 & 68 & 61 \\
Contabilidade ambiental & 71 & 32 & 39 \\
\hline
\end{tabular}

2003 e 2006 ambas sofreram reduções. A temática abordando custos ambientais em 2007 obteve a maior evolução de todo o período (oito estudos). Por outro lado, a temática contabilidade ambiental manteve-se estável entre 2006 e 2007 quando foram encontrados somente dois estudos abordando o assunto.

A Tabela 2 revela que, no geral, a temática custos ambientais ganhou maior atenção por parte dos pesquisadores representando $61 \%$, enquanto que 39\% dos estudos abordaram contabilidade ambiental. Entretanto a mesma tabela mostra que, quando separados por estudos nacionais e internacionais, existe um elevado número de estudos no âmbito internacional na temática contabilidade ambiental representando $71 \%$ contra 29\% que abordaram custos ambientais. Por outro lado, no Brasil, a situação se inverte, visto que os estudos em custos ambientais representaram $68 \%$ contra contabilidade ambiental com 32\%, caracterizando uma diferença no foco. Destaca-se que não se pode generalizar tal afirmação devido ao reduzido número de estudos internacionais disponíveis. Essa redução deu-se em virtude da falta de algumas bases internacionais como, por exemplo, o Proquest, tendo em vista que a CAPES não renovou o contrato com a ABI lnform Global, da Proquest, para o ano de 2008 (HAEFFNER, 2008), que se encontra limitada ao acesso somente às teses e dissertações.

Nas Figuras 2 e 3 encontram-se os tipos de estudos identificados na pesquisa. A Figura 2 (tipos de estudos internacionais) revela que os ensaios teóricos sobre 
contabilidade ambiental prevaleceram, uma vez que não foi identificado nenhum abordando o tema custos ambientais. Os modelos sugeridos para identificação, mensuração e contabilização dos custos ambientais foram encontrados apenas um para contabilidade ambiental e um para custos ambientais. Já os estudos descritivos não apareceram em nenhuma das temáticas nos tipos de estudos internacionais.

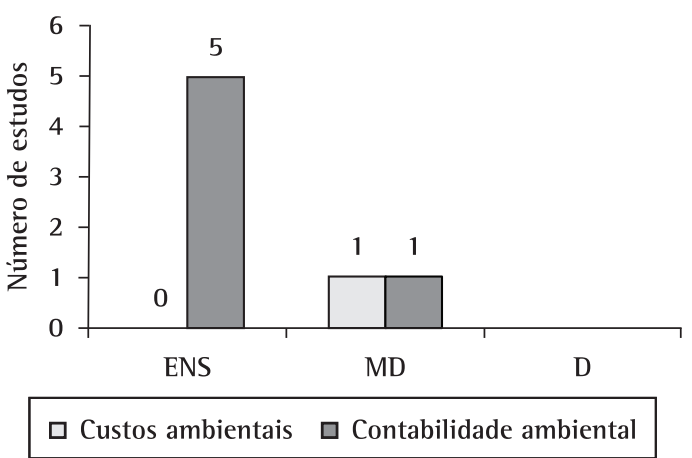

Figura 2. Tipos de estudos internacionais. ENS: Ensaio teórico; MD: Modelo sugerido; D: Estudos descritivos. Fonte: dados da pesquisa.

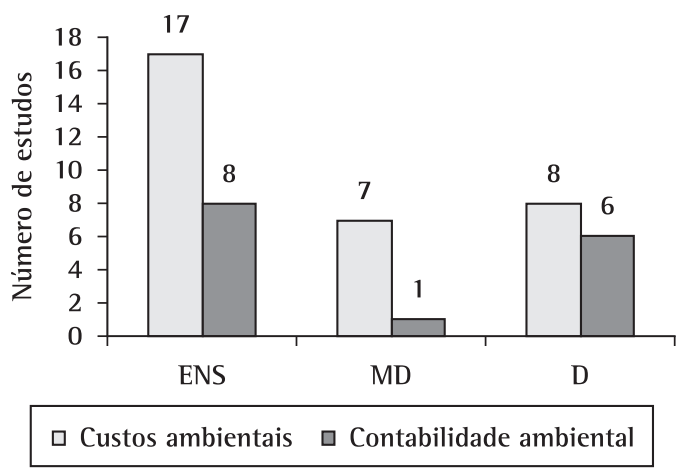

Figura 3. Tipos de estudos nacionais. Fonte: dados da pesquisa.

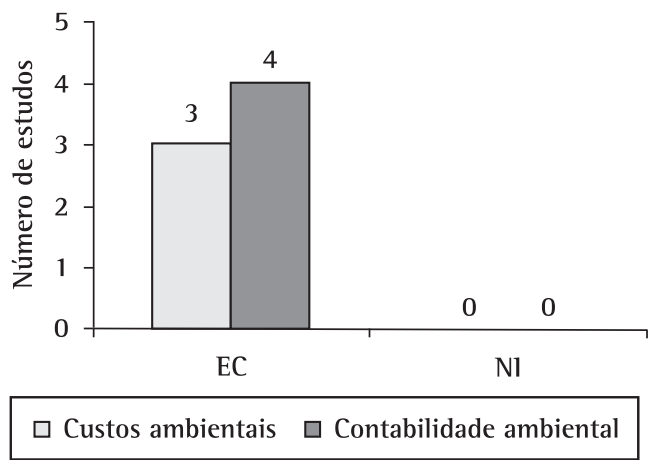

Figura 4. Estratégias de estudos internacionais. EC: Estudo de caso; Nl: Não identificado. Fonte: dados da pesquisa.
Ao contrário dos estudos internacionais, na Figura 3 é possivel observar uma inversão no tocante às temáticas, visto que, nos tipos de estudos nacionais, os ensaios teóricos em custos ambientais são a maioria ou mais que o dobro em relação aos ensaios teóricos que abordaram contabilidade ambiental. A mesma tendência é observada tanto nos modelos sugeridos para mensuração e contabilização dos custos ambientais quanto nos estudos descritivos nos tipos de estudos em âmbito nacional.

Nas Figuras 4 e 5 encontram-se as estratégias de estudos identificadas nos trabalhos.

A mesma tendência dos tipos de estudos pode ser visualizada nas estratégias de pesquisa utilizadas. $\mathrm{Na}$ Figura 4, a estratégia de pesquisa estudo de caso prevaleceu na temática contabilidade ambiental em âmbito internacional, enquanto que, no Brasil (Figura 5), a atenção por parte dos pesquisadores ficou mais centrada na temática custos ambientais, isto é, o dobro se comparado com contabilidade ambiental.

No que tange às fontes de publicações internacionais (Figura 6), os periódicos mantiveram a liderança tanto na temática custos quanto na temática contabilidade ambiental.

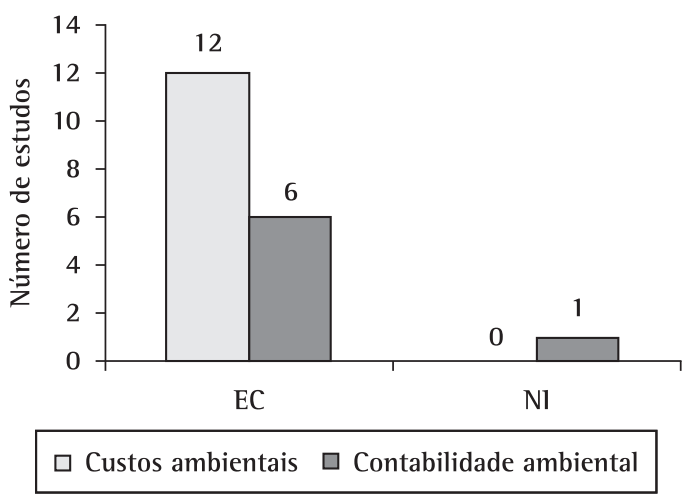

Figura 5. Estratégias de estudos nacionais. Fonte: dados da pesquisa.

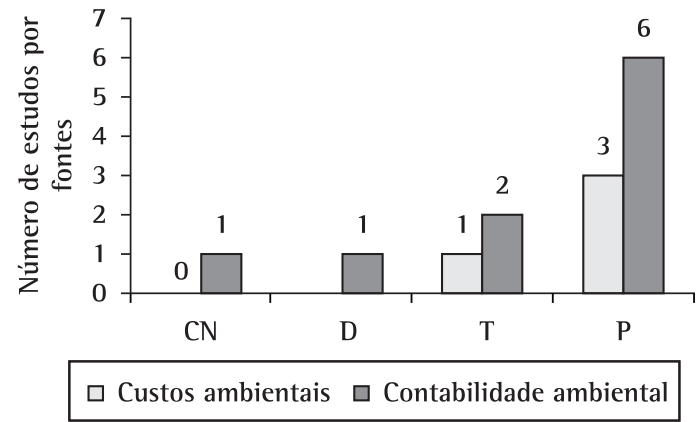

Figura 6. Fontes das publicações internacionais. CN: Congressos; D: Dissertações; T: Teses; P: Periódicos. Fonte: dados da pesquisa. 
Já na Figura 7 (fontes das publicações nacionais), os congressos lideraram o ranking das publicações nas duas temáticas; em dissertações houve estudos somente na temática custos ambientais, em teses

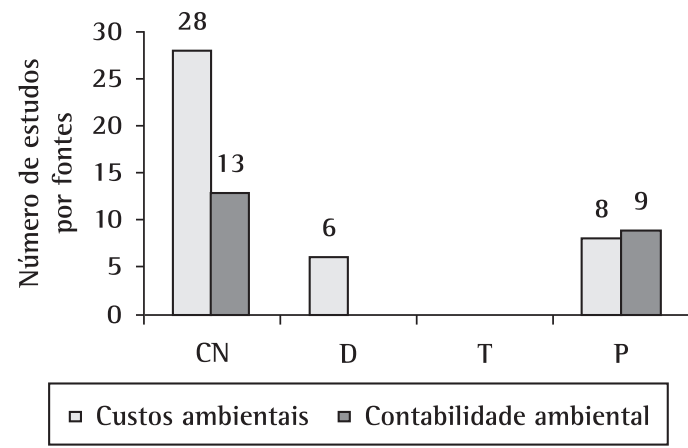

Figura 7. Fontes das publicações nacionais. Fonte: dados da pesquisa.

Tabela 3. Número de autores por artigo.

\begin{tabular}{ccc}
\hline Número de autores & Artigos & Percentual (\%) \\
\hline 1 & 35 & 43,75 \\
2 & 24 & 30,00 \\
3 & 9 & 11,25 \\
4 & 6 & 7,50 \\
5 & 4 & 5,00 \\
6 & 1 & 1,25 \\
Sem autores & 1 & 1,25 \\
Total & 80 & 100 \\
\hline
\end{tabular}

Fonte: dados da pesquisa. não foi encontrado nenhum estudo e em periódicos contabilidade ambiental liderou no número de publicações.

Na Tabela 3, diferentemente do estudo de Cardoso, Pereira e Guerreiro (2004), que analisaram os artigos do EnANPAD e identificaram $21,88 \%$ de artigos com um autor e 53,13\% com dois autores, no presente artigo esse perfil muda para $43,75 \%$ dos estudos realizados somente por um autor e 30\% com dois autores.

Essa mudança de perfil pode ter sido influenciada pelas teses e dissertações, visto que nestas aparece apenas um autor, enquanto que tanto em artigo de eventos como de periódicos geralmente encontra-se incluído também o nome do orientador. Outra característica foi a maior dispersão entre o presente estudo e o de Cardoso, Pereira e Guerreiro (2004), já que esses autores identificaram um número máximo de quatro autores por trabalho, enquanto para a presente pesquisa foram identificados estudos com até seis autores.

Uma visão panorâmica, na Tabela 4, diz respeito à concentração das publicações.

Pondera-se nesta Tabela 4 que quase 50\% das publicações estão concentradas em 13 autores, sendo dois deles internacionais (de Portugal e Chile). Do total de autores, apenas 8,78\% publicaram mais de um estudo e $91,22 \%$ publicaram apenas um abordando a questão contabilidade e/ou custos ambientais, o que caracteriza que existem ainda poucos autores difundindo essa área. Destaque para os autores Ribeiro, Eugênio, Campos e Kliemann Neto, com quatro publicações cada um.

Tabela 4. Número de artigos publicados segundo vínculo profissional dos autores.

\begin{tabular}{|c|c|c|c|c|c|}
\hline Autores & Instituição & Custos & Contabilidade & Total & $\%$ \\
\hline RIBEIRO, Maísa de S. & FEA-RP/USP & 3 & 1 & 4 & 5,00 \\
\hline EUGÉN10, Teresa C. P. & ISCAL - Portugal & & 4 & 4 & 5,00 \\
\hline CAMPOS, Lucila M. de S. & UFSC e UNIVALI & 4 & & 4 & 5,00 \\
\hline KLIEMANN NETO, Francisco J. & UFRGS & 4 & & 4 & 5,00 \\
\hline KRAEMER, Maria E. P. & UNIVAL1 & 1 & 2 & 3 & 3,75 \\
\hline DAVID, Afonso R. de & F. Santo André & 1 & 2 & 3 & 3,75 \\
\hline CALIXTRO, Laura & UFMG & & 3 & 3 & 3,75 \\
\hline BEN, Fernando & UCS & 3 & & 3 & 3,75 \\
\hline SELIG, Paulo M. & UFSC & 3 & & 3 & 3,75 \\
\hline FERREIRA, Aracéli C. de S. & UFRJ & 1 & 1 & 2 & 2,50 \\
\hline DURÁN, Orlando & Valparaíso - Chile & 2 & & 2 & 2,50 \\
\hline BORBA, José A. & CPGA/UFSC & & 2 & 2 & 2,50 \\
\hline POSSAMA1, Osmar & UFSC & 2 & & 2 & 2,50 \\
\hline Total de artigos & & 24 & 15 & 39 & 48,75 \\
\hline Total geral de artigos & & 49 & 31 & 80 & 100 \\
\hline Autores com mais de um artigo publicado & & & & 13 & 8,78 \\
\hline Autores com um artigo publicado & & & & 135 & 91,22 \\
\hline Total de autores & & & & 148 & 100 \\
\hline
\end{tabular}




\section{Considerações finais}

Este estudo objetivou contribuir para uma melhor visualização do cenário atual da produção acadêmica das temáticas contabilidade e custos ambientais. A pesquisa revelou que, embora com algumas oscilações, os estudos abordando esse tema cresceram, tendo em vista que em 1996 foram encontrados somente três estudos sobre custos ambientais e nenhum sobre contabilidade ambiental. No ano de 2007 já havia 49 que abordaram custos e 31 com a temática contabilidade ambiental, totalizando 80 no geral. Um fato interessante é que no Brasil a temática custos ambientais ganhou maior atenção por parte dos pesquisadores representando 68\%, contra 32\% dos estudos que abordaram contabilidade ambiental. No contexto internacional há uma inversão de foco, visto que a temática contabilidade ambiental representou $71 \%$ do total de estudos contra 29\% que abordaram custos ambientais.

Os ensaios teóricos sobre contabilidade ambiental prevaleceram no contexto internacional, mas não seguiram a mesma tendência para 0 contexto nacional, visto que no Brasil houve maior ênfase para custos ambientais. No âmbito nacional modelos propostos para identificação e mensuração dos custos ambientais foram sete vezes maior do que os modelos propostos para contabilização dos custos ambientais. Já no âmbito internacional houve um modelo proposto na temática contabilidade e um para custos ambientais.

Os estudos de caso também foram em maior número em contabilidade ambiental nos estudos internacionais, enquanto que no Brasil estes foram aplicados em sua maioria somente para avaliar os custos ambientais. No tocante às fontes de publicações no Brasil os estudos foram divulgados em maior quantidade nos anais de congressos, enquanto que no contexto internacional estes foram publicados em periódicos.

Pôde-se observar também que 8,78\% do total de autores publicaram mais de um estudo sobre o tema, os demais $91,22 \%$ tiveram apenas uma publicação na área, o que denota falta de continuidade de estudo sobre o assunto. Outra constatação foi que $43,75 \%$ das publicações foram com apenas um autor, o que aponta para a falta de grupos de estudos abordando o tema.

0 fato deste artigo ter optado por uma amostragem probabilística, com diversas fontes de publicação e apenas a leitura do resumo, pode ter levado à omissão de alguns estudos e/ou não terem sido identificadas corretamente as estratégias de pesquisa. Sendo assim, suas evidências e achados não podem ser generalizados, todavia devem ser entendidos como tendências e indicativos da evolução e preocupação sobre o tema pesquisado.
Portanto, os resultados apresentados contribuíram para caracterizar o perfil dos artigos publicados sobre as temáticas contabilidade e custos ambientais e evidenciar seus traços mais frequentes. Nota-se que houve um aumento significativo nos estudos abordando os temas de custos e contabilidade ambiental, no entanto, sugerem-se novos e mais aprofundados estudos, tais como surveys, a fim de identificar com maior precisão quais as contribuições desses trabalhos para a melhoria do meio ambiente.

\section{Referências}

ARKADER, R. A pesquisa científica em gerência de operações no Brasil. Revista de Administração de Empresas, v. 43, n. 1, p. 70-80, 2003.

BEUREN, 1. M.; SCHLINDWEIN, A. C.; PASQUAL, D. L Abordagem da controladoria em trabalhos publicados no EnANPAD e no Congresso USP de Controladoria e Contabilidade de 2001 a 2006. Revista Contabilidade \& Finanças da Universidade de São Paulo, v. 18, n. 45, p. 22-37, 2007.

CALIXTRO, L. Análise da pesquisa sobre contabTilidade ambiental no Brasil. Revista Brasileira de Contabilidade, n. 154, p. 23-35, 2005.

CAllado, A. L. C. A Importância da Gestão dos Custos Ambientais. Universo Ambiental. Disponível em: <http:// www.universoambiental.com.br/novo/artigos_ler.php? canal $=4 \&$ canallocal $=4 \&$ canalsub $2=10 \& i d=224 \&$ pagi na $=1>$. Acesso em: 23 abr. 2008.

CAllado, A. L. C.; AlMEIDA, M. A. Perfil dos artigos sobre custos no agronegócio publicados nos anais do Congresso Brasileiro de Custos. Custos e @gronegócio on line, v. 1, n. 1, p. 42-61, 2005.

CAMPOS, L. M. S. Um estudo para definição e identificação dos custos da qualidade ambiental. 1996. 165 f. Dissertação (Mestrado em Engenharia de Produção)-Universidade Federal de Santa Catarina, Florianópolis, 1996.

CAPON, N.; FARLEY, J. U.; HOENIG, S. Determinants of financial performance: a meta- analysis. Management Science, v. 36, n. 10, p. 1143-1159, 1990. http://dx.doi. org/10.1287/mnsc.36.10.1143

CARDOSO, R. L.; PEREIRA, C. A.; GUERREIRO, R. A produção acadêmica em custos no âmbito do EnANPAD: uma análise de 1998 a 2003. ln: ENCONTRO ANUAL DA ANPAD, 28., 2004, Curitiba. Anais... Curitiba: ANPAD, 2004.

CARDOSO, R. L. et al. Pesquisa científica em contabilidade entre 1990 e 2003. Revista de Administração de Empresas, v. 45, n. 2, p. 34-45, 2005.

DEGOS, J-G.; MATTESSICH, R. Accounting research in the French language area - second half of the 20th century. Review of Accounting and Finance, v. 5, n. 4, p. 423-442, 2006. http://dx.doi.org/10.1108/14757700610712471

FERREIRA, L. D.; MERCHANT, K. A. Field research in management accounting and control: a review and evaluation. Accounting Auditing \& Accountability Journal, v. 5, n. 4, p. 3-34, 1992. http://dx.doi. org/10.1108/09513579210019503 
GODOI, C. K.; BALSINI, C. P. V. A Metodologia Qualitativa nos Estudos Organizacionais: análise da produção científica entre 1997 e 2003. In: ENCONTRO DE ESTUDOS ORGANIZACIONAIS - ENEO, 3., 2004, Atibaia. Anais... Atibaia: ANPAD, 2004.

HAEFFNER, C. Acesso livre. [mensagem pessoal]. Mensagem recebida por<cristinah@capes.gov.br> em nome de cac $<$ cac@capes.gov.br> em 06 mar. 2008.

$\mathrm{Jl}$, X-D. Evaluation of research on chinese accounting. Managerial Finance, v. 26, n. 5, p. 41-62, 2000. http:// dx.doi.org/10.1108/03074350010766675

MARTINS, G. A.; DA SILVA, R. B. C. Plataforma teórica trabalhos do $3^{\circ}$ e $4^{\circ}$ congressos USP de Controladoria e Contabilidade: Um estudo bibliométrico. In: CONGRESSO USP DE CONTROLADORIA E CONTABILIDADE, 5., São Paulo. Anais... São Paulo: FEA/USP, 2005.

MATHEWS, M. R. Twenty-fiveyears of social and environmental accounting research. ls there a silver jubilee to celebrate? Accounting, Auditing \& Accountability Journal, v. 10, n. 4, p. 481-531, 1997. http://dx.doi.org/10.1108/ EUM0000000004417

MATHEWS, M. R. The development of social and environmental accounting research 1995-2000. Disponivel em: <www-accountancy.massey.ac.nz/docs/ Discussion\%20Paper/205.pdf>. Acesso em: 02 abr. 2008.

MENDONÇA NETO, O. R.; RICCIO, E. L.; SAKATA, M. G. Paradigmas de pesquisa em contabilidade no Brasil: ENANPAD: 1981-2005. In: ENCONTRO ANUAL DA ANPAD, 30., 2006, Salvador. Anais... Salvador: ANPAD, 2006.

MORETTI, S. L. A.; FIGUEIREDO, J. C. B. Análise bibliométrica da produção sobre responsabilidade social das empresas no EnANPAD: evidências de um discurso monológico. In: ENCONTRO ANUAL DA ANPAD, 31., 2007, Rio de Janeiro. Anais... Rio de Janeiro: ANPAD, 2007.

MOTTA, R. S. Indicadores ambientais no Brasil: aspectos ecológicos, de eficiência e distributivos. Rio de Janeiro: IPEA, 2006. Disponível em: <http://www.ipea.gov.br/ pub/td/1996/td_0403.pdf>. Acesso em: 24 abr. 2008.
RIBEIRO, M. S. Contabilidade ambiental. São Paulo: Saraiva, 2006.

RICCIO, E. L.; CARASTAN, J. T.; SAKATA, M. G. Accounting research at brazilian universities - 1962 - 1999. In: ASIAN-PACIFIC CONFERENCE, 11., 1999, Melbourne, Austrália. Proceedings... Melbourne, 1999.

ROBLES JUNIOR, A.; BONELll, V. V. Apuração dos Custos da Qualidade e dos Custos Ambientais Através da Contabilidade Baseada em Atividades. In: ENCONTRO ANUAL DA ANPAD, 25., 2001, Campinas. Anais... Campinas: ANPAD, 2001.

SÁNCHEZ; J. J. C. Algunas consideraciones de los costos medioambientales en los procesos productivos. Scientia Et Technica, n. 21, 2003.

SCHULTZ, C. A. et al. Produção científica na área de custos no setor de serviços no período de 2000 a 2004. Disponivel em: <http://www.congressoeac.locaweb.com. br/artigos62006/499.pdf>. Acesso em: 25 abr. 2008.

SHIELDS, D.; BELOFF, B.; HELLER, M. Environmental cost accounting for chemical \& oil companies:a benchmarking study. Disponível em: <http://permanent.access.gpo.gov/ lps6491/bench.pdf> Acesso em: 25 abr. 2008.

TONELLl, M. J. et al. Produção acadêmica em recursos humanos no Brasil: 1991-2000. Revista de Administração de Empresas, v. 43, n. 1, 2003.

VIEIRA, F. G. D. Narciso sem espelho: a publicação brasileira de marketing. Revista de Administração de Empresas, v. 43, n. 1, 2003.

YAKHOU, M.; DORWEILER, V. P. Environmental accounting: an essential component of business strategy. Business Strategy and the Environment, v. 13, n. 2, p. 65, 2004. http://dx.doi.org/10.1002/bse.395

\section{Agradecimentos}

Agradecemos ao CNPq (Edital Universal no 14/2008) e à FAPEMAT pelo apoio financeiro que possibilitou a realização desta pesquisa.

\title{
Environmental accounting and environmental costs: an analysis of the scientific production from 1996 to 2007
}

\begin{abstract}
This research aims to analyze the scientific production on accounting and environmental costs in the time period between 1996 and 2007. Environmental accounting and environmental costs were the key words used for thematic classification. The following aspects were analyzed: type of study, searching strategy, and academic affiliation of the authors. The results showed a growth in the two themes - from 3 studies in 1996 to 10 studies in 2007, in a total of 80 studies in that period. Overall, the environmental costs theme gained greater attention from researchers, representing $61 \%$, against $39 \%$ of the studies that addressed the environmental accounting theme. It was observed that, of the 148 authors identified, 13 were responsible for $48.75 \%$ of the publication total. This research aimed to contribute to the demonstration of the 'state of the art' on accounting and environmental costs, in the domestic and international contexts.
\end{abstract}

Keywords

Environmental accounting. Environmental costs. Scientific production. 